\title{
Who Controls the Content of Supreme Court Opinions?
}

\author{
Cliff Carrubba Emory University \\ Barry Friedman New York University \\ Andrew D. Martin Washington University in St. Louis \\ Georg Vanberg University of North Carolina at Chapel Hill
}

\begin{abstract}
Conventional arguments identify either the median justice or the opinion author as the most influential justices in shaping the content of Supreme Court opinions. We develop a model of judicial decision making that suggests that opinions are likely to reflect the views of the median justice in the majority coalition. This result derives from two features of judicial decision making that have received little attention in previous models. The first is that in deciding a case, justices must resolve a concrete dispute, and that they may have preferences over which party wins the specific case confronting them. The second is that justices who are dissatisfied with an opinion are free to write concurrences (and dissents). We demonstrate that both features undermine the bargaining power of the Court's median and shift influence towards the coalition median. An empirical analysis of concurrence behavior provides significant support for the model.
\end{abstract}

$\mathrm{D}$ ecisions by the U.S. Supreme Court have great public significance. Its opinions direct the decisions of lower courts, shape public policy, and affect the behavior of private individuals. Because judicial opinions matter, and because they emerge from deliberations largely hidden from public view, it is not surprising that there has been great interest in understanding whether some members of the Court are more influential in shaping opinions than others. Indeed, the suspicion that particular justices-and their replacementsare particularly important underpins a common distinction between "critical" appointments and those that are less important (Ruckman 1993). In short, understanding which justices are influential in shaping Supreme Court opinions is a central puzzle not just in the study of the
Court, but in understanding its impact on the broader political system.

The scholarly literature-both in political science and in law-has, by and large, offered two answers. One highlights the importance of the Court's center. According to "median justice" theories, the median justice has sway over the content of opinions because she is critical to building a majority in support of a particular decision (e.g., Epstein et al. 2005; Martin, Quinn, and Epstein 2005). In contrast, other scholars have pointed to the influence of opinion writers. These "opinion author" theories argue that authorship confers agenda-setting powers that allow those who draft opinions to exercise considerable influence (Bonneau et al. 2007; Hammond, Bonneau, and Sheehan 2005; Lax and Cameron 2007; Maltzman,

Cliff Carrubba is Associate Professor of Political Science, Emory University, 1555 Dickey Drive, Atlanta, GA 30322 (carrub@emory.edu). Barry Friedman is the Jacob D. Fuchsberg Professor of Law, New York University School of Law, 40 Washington Square, South, New York, NY 10012 (friedmab@exchange.law.nyu.edu). Andrew D. Martin is Professor of Political Science and Law, Washington University in St. Louis, Campus Box 1063, One Brookings Drive, St. Louis, MO 63130 (admartin@wustl.edu). Georg Vanberg is Professor of Political Science, University of North Carolina at Chapel Hill, Chapel Hill, NC 27599 (gvanberg@unc.edu).

We would like to thank Chuck Cameron, Tom Clark, Lewis Kornhauser, Jeff Lax, and participants at workshops at Duke University, New York University, Princeton University, the University of Rochester, and the University of Texas for comments on earlier versions of this article. We would also like to thank six anonymous referees for valuable comments on earlier versions of this mansucript. Friedman's work was supported by the Filomen D’Agostino and Max E. Greenberg Research Fund at New York University School of Law. Martin's work was supported by The Center for Empirical Research in the Law at Washington University Law School. L. Rush Atkinson, Brian Burgess, and Josh Levy provided valuable research assistance. Replication data, robustness checks, and formal proofs of results can be accessed at http://www.unc.edu/ gvanberg/Research.html.

American Journal of Political Science, Vol. 56, No. 2, April 2012, Pp. 400-412

(C) 2011, Midwest Political Science Association

DOI: $10.1111 / \mathrm{j} .1540-5907.2011 .00557 . \mathrm{x}$ 
Spriggs, and Wahlbeck 2000). ${ }^{1}$ In these models, the final opinion reflects the preferences of the opinion author, although it may be sensitive to the preferences of the median, depending upon the relative positions of the two actors and, in some models, the position of the status quo. In short, most theoretical literature focuses on the influence of the median justice and the opinion author and leads to the expectation that opinions reflect (a combination) of their preferences.

In this article, we develop a model of decision making on collegial courts that offers a different answer. ${ }^{2}$ The critical implication of our model is that opinions are likely to reflect the views of the median justice in the majority coalition. ${ }^{3}$ This result derives from two features of judicial decision making that have received little attention in previous models. The first is the fact that in deciding a case, justices must first and foremost resolve a concrete dispute. In addition to preferences over legal rules, justices may have preferences over which party wins the case confronting them. ${ }^{4}$ The second feature is that justices who are dissatisfied with the opinion written in support of a decision are free to write concurrences (and dissents). Taking account of both features is significant because it implies that justices will be reluctant to "switch sides" between the majority, which favors one disposition, and the minority, which favors another disposition. Moreover, given the ability to write separate opinions, they have no need to do so. In consequence, bargaining power shifts to the median justice of the majority coalition.

We demonstrate this dynamic formally by making the-potentially controversial-assumption that justices care sufficiently about the disposition to be unwilling to switch sides. Focusing on this boundary case allows us to highlight the impact of preferences over dispositions on bargaining power. Nevertheless, as we argue below, and then demonstrate empirically, the logic we identify is relevant for decision making on collegial courts more generally as long as justices care somewhat about dispositions, even if they are (ultimately) willing to switch sides. This finding has profound implications for the content of

${ }^{1}$ Lax and Cameron (2007) offer an innovative variation that focuses on the nature of language and relies on variation in writing ability to generate opinion writer influence.

${ }^{2}$ In focusing on the internal dynamics of judicial bargaining, we leave aside external factors such as separation of powers (e.g., see Clark 2011; Owens 2010; Segal 1997).

${ }^{3}$ Westerland (2003) also points to the potential influence of the coalition median, but provides no explicit theoretical foundation for this influence.

${ }^{4}$ The assumption that justices care about both the rule and disposition is novel; existing literature treats the disposition as secondary to the rule.
Supreme Court opinions because it suggests that opinions are systematically less centrist than implied by traditional approaches, in particular by median justice theories. The rest of the article is organized as follows. In the next section, we provide background to justify our approach. We then present our model. The third section provides empirical support for the central implications of our theory. The final section concludes.

\section{Dispositions, Rules, and Expressive Preferences}

To motivate our model, it is useful to sketch the difference between traditional approaches and our argument. When justices decide cases, they perform two (related) tasks. They dispose of the controversy before them by determining which of the two contending parties wins. This is the "disposition" of the case. Second, justices explain why they arrived at a particular disposition. This is the "rationale" of the opinion, which provides the "legal rule" that governs future cases. ${ }^{5}$ Naturally, rules and dispositions are related: a specific rule determines-for a given set of facts-which of the two parties ought to win. ${ }^{6}$ Most traditional approaches, including "median justice" and "opinion writer" models, focus exclusively on the choice of legal rule, assuming that justices attempt to move the Court's opinion as close as possible to their own most preferred legal rule (e.g., see Epstein and Knight 1998; Ferejohn and Weingast 1992). Implicitly, this assumes that justices do not care independently about the disposition of the case in front of them; that is, they do not care inherently about whether the party that ought to win under their preferred legal rule actually does. What matters is that the legal rule adopted by the Court is close to the justice's preferred legal rule. ${ }^{7}$

The fact that justices do not care independently about the disposition of cases is crucial to these models because

${ }^{5}$ Note that Spaeth's U.S. Supreme Court Database uses dispositions ("direction") as a proxy measure for the legal rule (see http: //supremecourtdatabase.org/).

6"Case space models" (see Kornhauser 1992; Lax 2007; Lax and Cameron 2007) explicitly model the connection between rules and dispositions as cutpoints that divide a case-space into cases that are "winners" and "losers."

${ }^{7}$ In the context of spatial models, the point can be expressed this way: Consider a justice whose ideal legal rule is $L$, which awards victory to Smith over Jones. Given rule $A$ (which awards victory to Jones) and $B$ (which awards victory to Smith), the justice prefers $A$ to $B$ whenever $A$ is closer to $L$ (even if $B$ is only marginally further away from $L$ than A) despite the fact that $A$ implies victory for the "wrong" party. 
it implies that justices are willing to "switch sides" between the (current) majority (which supports one disposition) to the (current) minority (which supports the other disposition). To see why this is significant, consider an example. Suppose the Supreme Court is deciding a capital case involving the question whether a jury is entitled to hear "victim impact" evidence. The trial judge admitted such evidence, and the jury imposed the death sentence. The appellate court affirmed. The "disposition" question before the Supreme Court is whether to uphold or reverse the death sentence. The "legal rule" question is when (i.e., to what extent, or under what circumstances) victim impact evidence should be admissible. Suppose there are four votes on the Court to reverse the death sentence on the grounds that victim impact evidence should never be admissible, and four votes to affirm on the ground that it should always be admissible. The median justice votes in the Court's initial conference to reverse the death sentence because she believes that the particular evidence presented unfairly tainted the jury. However, when she sees the draft opinion, she disagrees with the legal rule articulated in the opinion: in her view, victim impact evidence ought to be admissible sometimes, while the draft opinion argues that it never should be.

Under existing models, bargaining would now commence for the vote of the median justice. Those seeking to allow victim impact evidence would moderate their view, hoping to attract the median to their side. Those seeking to ban such evidence would tone down their preferred rule in order to prevent the median's defection. That is, the threat to "switch sides" provides the median justice with bargaining power, and the opinion that emerges should therefore reflect her views. But note that the median's decision to defect to a more attractive rule could carry with it the implication that the petitioner before the Court will be put to death! Putting it differently, because "switching sides" implies that she would need to vote in favor of a disposition with which she disagrees (namely, to uphold the death sentence), the median's threat to switch sides is only credible if she does not care (sufficiently) what happens to the petitioner in the current case.

Suppose-for argument's sake - that the median justice does care which party wins, i.e., that she prefers not to uphold the death sentence. If this is the case, her bargaining power is undermined because other justices should recognize that - at least within limits-not giving in to the median's demands will not result in her defection to the minority.

A second feature of judicial decision making reinforces this dynamic. A justice who is dissatisfied with the opinion offered in support of a disposition is free to write a concurrence, which allows her to support the disposi- tion, but to do so by offering her own preferred rationale. That is, a justice is always free to "say what she thinks" without having to join another coalition of justices. (We suspect that justices have strong preferences for "saying what they think," and refer to this desire as indulging one's "expressive preferences"). ${ }^{8}$ The availability of this option further weakens the incentive to "defect" - a justice who disagrees with an opinion need not join the other side to express her disagreement. Knowing this, other justices have less reason to fear a defection, and therefore less incentive to be accommodating.

Of course, the assumption that justices care independently about the disposition of cases, rather than purely about the legal rules that emerge from them, is critical to this approach. How plausible is it that justices care about resolving cases in a manner that awards victory to the party that they believe ought to win? As a brief scan of a constitutional law text or the Supreme Court's docket suggests, cases often pose salient controversies in which justices are likely to have preferences over the resolution of the particular case. Consider Youngstown Steel. While justices clearly cared about the legal principles announced in the decision - which would affect the limits of presidential power in the future-it is hard to imagine that they did not also care about the immediate results of the decision: namely, whether President Truman would retain possession of the nation's steel mills. Similarly, in decisions surrounding the constitutionality of federal statutes, it seems implausible that justices care only about legal rules, but disregard the immediate consequences for the dispute. Can the federal government mandate purchase of health insurance coverage by individuals? While preferences over the interpretation of the Commerce Clause, and implications of this interpretation for congressional power, are important, it is highly unlikely that the justices do not consider the implications for health care reform in deciding this issue. Indeed, the famous legal adage "Hard cases make bad law" points precisely to the fact that because justices care about the outcome of the dispute in front of them, legal rules may be (inappropriately) influenced by the desire to craft a rule that supports a particular outcome. As Oliver Wendell Holmes elaborated in his dissent in Northern Securities Co. v. United States (1904):

Great cases like hard cases make bad law. For cases are called great, not by reason of their real importance in shaping the law of the future, but

\footnotetext{
${ }^{8}$ Consider Justice John Paul Stevens's statement that " $[t]$ here is a duty to explain your position if it isn't the same as the majority, and it's just part of my thinking about what a judge should do" (quoted in a New York Times story on Stevens's impending retirement, April 9, 2010.)
} 
because of some accident of immediate overwhelming interest which appeals to the feelings and distorts the judgment. ${ }^{9}$

In short, unlike most traditional approaches (which focus on the choice of legal rule, disregarding the possibility that justices have [independent] preferences over the disposition, and abstract away from the ability to write a concurrence), the model we develop in the next section assumes that justices care about rules and dispositions, that they have expressive preferences, and that they have the option of writing concurrences if they are dissatisfied with the proposed majority opinion. As we show, taking these features into account leads to very different conclusions regarding the bargaining dynamics on collegial courts.

\section{Modeling a Collegial Court}

We consider a one-dimensional "case fact" model with a five-member court. A case is represented as a point, $c \in R$. A legal rule is a threshold such that case facts to the left of the threshold imply judgment in favor of one party, while case facts to the right result in a judgment for the other party. For example, the fact space might represent the intrusiveness of a police search, and a particular case involves a dispute over the constitutionality of a search of a given level of intrusiveness. A legal rule indicates how "intrusive" a search may be before it is deemed unconstitutional. Each justice has a most preferred legal rule, denoted by the threshold $x_{i} \in R$.

We assume that justices are motivated by several considerations that enter as additive terms into their utility functions. First, they care about the legal rule announced in a majority opinion (if one is issued.) A majority opinion has precedential value, and it is likely to carry particular weight in shaping "the law" precisely because it enjoys the support of a majority of the Court's justices. We capture this aspect through standard spatial preferences. Letting $p \in R$ denote the legal rule adopted in a majority opinion, each justice receives a policy payoff of $K-\left|x_{i}-p\right|$. The parameter $K>0$ captures the value that justices place on establishing a legal rule that perfectly reflects their rule preferences. Because this term captures the "policy payoffs" of majority opinions, it only enters the justices' utility functions if the opinion attracts a majority of votes.

${ }^{9}$ See online Appendix I: The Impact of Dispositions on Judicial Decision Making for additional supporting material on this point.
Second, justices care about the disposition of a case. Independent of the legal rule adopted by the Court, a justice derives some utility from a decision that reaches the "right" result. The parameter $\alpha>0$ captures this aspect and is added to a justice's payoff if the party favored by the justice prevails. Finally, we assume that justices have "expressive" preferences: they prefer that the opinions they sign, and with which they are therefore identified, reflect their sincere preferences. Letting $e_{i}$ denote the legal rule expressed in an opinion the justice signs and $D_{x i}$ indicate whether that opinion reaches the disposition preferred by the justice, the justice's expressive benefits are given by $\beta\left(K-\left|x_{i}-e_{i}\right|+D_{x i} \alpha\right)$. The parameter $\beta>0$ reflects the weight that justices place on expressive benefits.

We assume that expressing disagreement with a majority opinion via a concurrence or dissent is costly. Writing separately requires time and effort. Moreover, if justices value consensus (see Corley 2010, 27), there are costs to taking a public position that disagrees with the majority. Finally, for justices considering concurring opinions, another consideration is relevant. While a concurring opinion allows a justice to express her most preferred rule, it also exposes divisions within the majority that may undermine the authority of the Court's ruling (see Corley 2010, 54). Chief Justice John Marshall's push for issuing "Opinions of the Court" rather than seriatim opinions was driven, at least in part, by this concern (Carrington 1992; Haskins and Johnson 1981). In our model, the parameter $c>0$ captures costs that a justice bears for writing separately.

Putting these components together generates an additive utility function that represents the justices' preferences. For example, a justice who agrees with the majority's disposition and simply joins the majority opinion collects the policy and expressive payoffs of that opinion:

$$
U_{i}(\text { Join })=(1+\beta)\left(K-\left|x_{i}-p\right|+D_{x_{i}} \alpha\right)
$$

Or, if the same justice writes a concurrence to explain any differences between the majority opinion and her own position, she collects the policy payoff of the majority opinion (since it is this opinion that has precedential value), but receives the expressive payoff associated with her concurrence (less the cost of writing separately), where $e_{i}$ denotes the legal rule expressed in the concurrence:

$$
\begin{aligned}
U_{i}(\text { Concurrence })= & K-\left|x_{i}-p\right|+\alpha \\
& +\beta\left(K-\left|x_{i}-e_{i}\right|+D_{x_{i}} \alpha\right)-c
\end{aligned}
$$

For the remainder of the article, we assume that expressive and dispositional preferences are sufficiently important that justices are not willing to support an opinion 
that results in a disposition with which they disagree. ${ }^{10}$ This is, of course, a potentially controversial assumption that characterizes a boundary case and does not hold for all (or even most) cases decided by the Supreme Court. We focus on this case because it eases the exposition and allows us to highlight the logic we identify and to contrast this model with the underlying dynamic and predictions of previous models. Having said that, the implications of the model are not confined to those cases in which the assumption holds. As long as justices care independently about the disposition of cases, they will be willing to trade victory for the "right" party for some concessions on the legal rule- and that is enough to undermine the bargaining power of the median justice and to provide the coalition median with a measure of influence over opinions as identified by our model. Indeed, our empirical analysis clearly reveals the influence of the coalition median, thus providing indirect evidence of the model's relevance to a broad class of decisions.

\section{Opinion Location and Concurrence Behavior}

If justices are not willing to "switch sides," they divide into a proto-majority and proto-minority according to their preferences over case disposition. Bargaining over the majority opinion proceeds only among the justices in the proto-majority. In analyzing this bargaining process, we make no assumptions about the bargaining protocol. Instead, we allow for free-flowing bargaining that enables easy input from the justices of the proto-majority. This assumption captures the fact that bargaining on the Supreme Court has little formal structure and proceeds in an open fashion. ${ }^{11}$ Because "median justice" models rest on the assumption of costless bargaining among the justices, this assumption also ensures that differences between our model and median justice models are not the result of introducing bargaining costs.

Let $M$ denote the set of justices in the proto-majority. For every legal rule $p \in R$, define $C(p)$ as the set of jus-

\footnotetext{
${ }^{10}$ Formally, the following constraint is sufficient (but not necessary) to ensure that a justice in the majority will not "switch sides:" $\alpha \geqq$ $\frac{K+c}{1+\beta}$. That is, the constraint is derived for a justice with the strongest incentive to defect and therefore identifies the largest possible value of $\alpha$ required to prevent a defection; as we demonstrate in the appendix, in most circumstances, justices will not defect even if $\alpha$ is below this threshold. The appendix also provides the condition that prevents minority justices from switching to the majority side.

${ }^{11}$ See Maltzman, Spriggs, and Wahlbeck (2000) for a detailed treatment of the bargaining process, including the use of threats, suggestions, and wait statements by the justices.
}

tices who are willing to sign an opinion written at $p$. Define the set of potential majority coalitions, $P C=$ $\{C(p):\|C(p) \geq 3\|\}$. In words, $P C$ identifies the possible majority coalitions, that is, the coalitions that are able to agree on an opinion that enjoys majority support. Because all coalitions in PC constitute a majority of the court, if there are two or more potential coalitions, any two coalitions must have members in common.

We characterize the bargaining process among the justices in the proto-majority as follows. Initially, an opinion writer is (exogenously) assigned. The opinion writer proposes an opinion. Bargaining then proceeds under an open rule: other justices are able to make costless counterproposals (i.e., suggest changes in the opinion). Assuming costless bargaining allows us to explore opinion writer influence that does not rely upon previously derived sources of influence, such as formal agenda-setting powers (see Hammond, Bonneau, and Sheehan 2005; Lax and Cameron 2007; Maltzman, Spriggs, and Wahlbeck 2000). Once a stable opinion emerges (more on that below), each justice in the proto-majority decides what action to take. She can join the opinion, write a general concurrence (join the opinion but also add some additional comments in a concurrence), write a special concurrence (do not join the opinion but write separately), or do none of the above.

To identify the location of opinions, we adopt the following cooperative solution concept. First, we assume that justices can only "vote" for an opinion if they are willing to sign it (i.e., join or join and concur). This restriction ensures that justices cannot influence bargaining through noncredible threats. For example, suppose we have a proto-majority consisting of justices ordered one through four. Justice 1 is the opinion writer for a proto-coalition composed of justices 1 through 3. Justice 4 is so distant ideologically from this proto-coalition that he is unwilling to sign any opinion that justices 2 and 3 would sign. In this scenario, justice 4 should be unable to influence the outcome; since 4 will never sign any opinion that 2 and 3 would sign, justices 2 and 3 cannot use an alternative coalition with justice 4 as bargaining leverage over justice 1.

Second, we assume that a majority opinion at $p$, enacted by proto-coalition $C(p)$, is stable if and only if two conditions are met:

1) There does not exist an alternative majority opinion $\hat{p}$ that can be enacted by proto-coalition $C(\hat{p})$ such that $\forall i \in C(p) \cap C(\hat{p}), U_{i}(\hat{p})>U_{i}(p)$.

2) There does not exist an alternative majority opinion $\hat{p}$ that all members of $C(p)$ are willing to sign and that a majority of $C(p)$ prefers to sign. 


\section{FIGURE 1 Justice $i$ 's Voting and Concurrence Decisions as a Function of Opinion Location When $c \leq \beta k$}

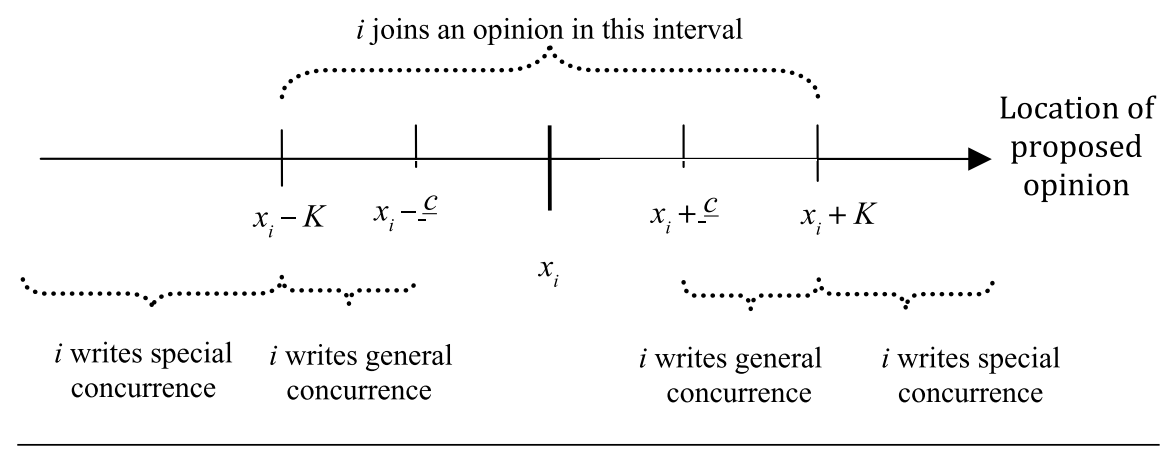

To see the logic of the first condition, consider the supermajority case. Suppose there are four members of the proto-majority, and justice 1 has written an opinion that justices 1 through 3 are willing to sign. However, justices 2 through 4 can agree on an alternative majority opinion that justices 2 and 3 prefer to the opinion by 1 . Justice 1's opinion is unstable because some members of l's coalition can join another coalition that can write a majority opinion the defectors prefer.

The second condition adds a within-proto-coalition majority requirement. If a majority of the members of the proto-coalition prefer another opinion to the one offered by the opinion writer, and all members of the proto-coalition are willing to sign that alternative, then we consider the proposal made by the opinion writer to be unstable: opinion writers who are willing to support an opinion preferred by a majority of their coalition cannot "hold out."

\section{Opinion Content in Equilibrium}

We reserve derivation of the model's predictions to the online appendix. ${ }^{12}$ Here, we focus on characterizing the implications for the location of the majority opinion and for concurrence behavior. It is easiest to describe the intuition by considering the decision calculus of an individual justice in the proto-majority. Suppose an opinion $p$ has been reached, and the justice must decide whether to join, concur, or do neither. The trade-offs are clear: by signing the majority opinion, she can save the trouble of writing a concurrence. On the other hand, if she chooses to join and not write a concurrence, she is publicly identified with the opinion. Not surprisingly,

\footnotetext{
${ }^{12}$ Available at http://www.unc.edu/ gvanberg/Research.html.
}

justices are willing to join opinions that are relatively close to their own ideal point and not write a concurrence. Once an opinion deviates sufficiently from a justice's ideal point, she chooses to concur to give voice to her preferred legal rule. Figure 1 illustrates the justice's behavior.

One important implication is that a majority opinion is only possible if there exists a group of justices who form a majority and whose preferences are sufficiently homogenous: there must be overlap between the "join regions" of the justices. For example, suppose the proto-majority is composed of three justices, all of whose votes are necessary to create binding precedent. Let the justices' ideal thresholds be ordered $x_{1}<x_{2}<x_{3}$. It is only possible to find a majority opinion if there exists a rule that both 1 and 3 are willing to sign. This is the case if $x_{3}-K<x_{1}+K$, i.e., if the distance between the two justices' ideal rules is less than $2 K$. If the protomajority contains a supermajority, there may be multiple "proto-coalitions" that are sufficiently homogenous to be able to agree on a majority opinion. ${ }^{13}$ The following statement summarizes where majority opinions will be located:

Equilibrium Majority Opinion Location: If a majority opinion emerges, the rule adopted in the opinion is either (a) the most preferred rule of the median member of the coalition who signs the opinion, or (b) the rule closest to the rule most preferred by the median member of the signing coalition that all members of the signing coalition are willing to sign.

\footnotetext{
${ }^{13}$ As we show in the appendix, all members of a proto-coalition prefer to join a binding opinion that is located in the "join interval" of the proto-coalition to not establishing binding precedent. As a result, if a proto-coalition exists, a majority opinion will emerge.
} 


\section{FIgURE 2 Example of Opinion Location}

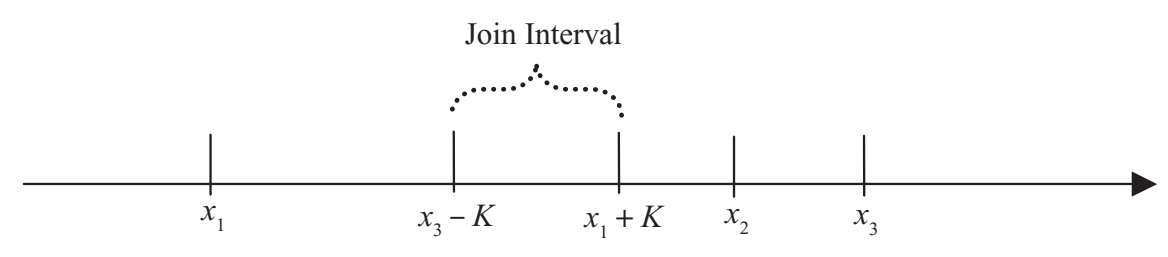

The intuition behind this result is straightforward. Because justices are unwilling to switch sides on the disposition of the case, the median member of the Court as a whole has lost her central position in the bargaining process. Instead, bargaining among the members of the proto-majority is concentrated in the group of justices who will write the majority opinion. It is the median within this group who now holds central sway-but this sway is subject to a caveat: the median member of the proto-coalition will only "get her way" if her most preferred rule is acceptable to all members of the protocoalition. In some circumstances, this may not be the case: a justice whose signature is necessary to unite a majority behind the opinion may not be willing to join an opinion at the median's ideal point. In such a case, the median must (and, given the homogeneity of the proto-coalition, is willing to) make sufficient concessions to bring this justice on board. Nevertheless, this rule will reflect the preferences of the median of the signing coalition better than the views of her more extreme colleagues who also join.

Figure 2 provides an illustration of the case of a minimal-winning proto-majority. The "join interval" that identifies the set of opinions all three justices are willing to sign (and prefer to the failure to establish precedent) is located to the left of the ideal rule preferred by the median of the signing majority (justice 2). Justices 2 and 3 are able to draw the opinion to the right, but not past $x_{1}+K$ because they need (and prefer) to keep justice l's vote. Thus, the opinion is located at the right end of the join interval, closest to the rule preferred by the signing coalition median.

If the preferences of justices are so heterogeneous that no proto-coalition exists, no majority opinion is possible. In this case, the plurality opinion will be written at the ideal point of the opinion writer:

Equilibrium Plurality Opinion Location: If a plurality opinion emerges from the bargaining process, the rule adopted in the opinion is located at the most preferred rule of the opinion writer.
In short, one important substantive implication of our model is that if justices care both about the rule and the judgment announced in an opinion, the influence of the median justice (of the Court) over majority opinions is typically not as strong as conventional arguments imply. Instead, bargaining power shifts towards the position of the median member of the signing coalition of the opinion.

\section{Data and Measures}

In this section, we develop an empirical test of our model. The model generates implications for the location of opinions and the concurrence behavior of justices. While reliable data on concurrences are readily available, estimating the location of Supreme Court opinions has proven challenging (e.g., McGuire and Vanberg 2007). We therefore focus on testing the model's implications for the concurrence behavior. ${ }^{14}$ In the model, a justice concurs if and only if the proposed policy is not sufficiently close to her ideal point, i.e., $p \notin\left[x_{i}-\frac{c}{\beta}, x_{i}+\frac{c}{\beta}\right]$. Furthermore, majority opinions are located at (or close to) the most preferred rule of the median of the signing coalition, while plurality opinions are located at the opinion writer's ideal point. As a result, when an opinion is supported by a majority (plurality), the further a justice is from the median of the signing coalition (the opinion writer), the less the content of the opinion reflects her views.

Hypothesis: For majority opinions, the more ideologically distant a justice is from the median of the signing coalition, the more likely that

\footnotetext{
${ }^{14}$ In an important recent article, Clark and Lauderdale (2010) develop a method for estimating the position of Supreme Court opinions using cross-citation patterns. In their illustration of the method, they test the opinion location prediction of our model against median justice theory and opinion writer models. Their results suggest that the preferences of the majority coalition median are the best predictor of opinion location, a result that is consistent with our model, and inconsistent with the alternative theories.
} 
justice is to concur. For plurality opinions, the more ideologically distant a justice is from the opinion writer, the more likely that justice is to concur.

This hypothesis stands in contrast to the implications of conventional median justice theory, which predicts that concurrence behavior is a function of distance to the overall Court median, and to models that predict strong opinion writer influence, which predict that concurrence behavior is predicted by distance to the opinion writer in all cases, not just for plurality opinions. ${ }^{15}$ An analysis of concurrence behavior therefore holds out the possibility of adjudicating between these arguments.

The data for our analysis come from the U.S. Supreme Court Judicial Database (Spaeth 2006) and cover the 1953 through 2005 terms. ${ }^{16}$ The dependent variable is the decision by a justice in the majority to file a special or general concurrence. The key independent variables include a justice's ideological distance to the coalition median, the Court's median, and the opinion writer, and an indicator for majority and plurality opinions.

To measure the position of each justice, we rely on Martin-Quinn scores, which place justices in a onedimensional ideological space (Martin and Quinn 2002). These scores are dynamic, allowing the location of each justice to evolve over time, and they classify well across issue areas. ${ }^{17}$ For the analyses that follow, we only include cases in which there is perfect spatial voting (with participation by all members of the Court) based on estimates of the spatial locations of the justices. We do so to minimize the possibility that the results might be confounded by decisions resting on factors other than ideological differences among the justices. ${ }^{18}$

\footnotetext{
${ }^{15}$ Naturally, other factors may affect the propensity to concur, including personal temperament. However, it is not clear that these idiosyncratic factors are systematically related to a justice's ideological position on the Court.

${ }^{16}$ The unit of analysis is the case citation $(A N A L U=0)$. Decisions included are formally decided cases issued with written opinions after full oral argument and cases decided by an equally divided vote (DEC_TYPE $=1,5,6,7)$. The findings are robust if the docket, rather than the case citation, is the unit of analysis (see online Appendix Table 10).
}

${ }^{17}$ Using M-Q scores to predict votes on the merits raises issues of endogeneity because votes are used to create the scores. This problem does not arise here because decisions to concur are not used in the construction of the measure.

${ }^{18}$ Perfect spatial voting occurs when the majority and minority coalitions are connected. We focus on these cases because we are more comfortable using cases that resolve in a manner consistent with the underlying measurement model. Our substantive results are robust to including cases without perfect spatial voting (see

\section{Results}

As a first cut, Table 1 summarizes the number of special concurrences for each coalition type in the dataset; e.g., all 5-4, 6-3, 7-2, 8-1, and unanimous coalitions. For example, in the 2005 term, a "6-3 Right" coalition is a coalition in which Justices Breyer through Scalia are in the majority. A "6-3 Left" coalition refers to a majority comprised of Justice Stevens through Kennedy, and so on.

Consistent with our theory's prediction, the median of the majority coalition (where that median differs from the median of the Court) concurs less often than the median of the Court. Further, concurrences generally increase as one moves away from the median of the coalition. The patterns in the "Right" coalitions are especially striking. These results are broadly consistent with our hypothesized relationship and inconsistent with median justice theory.

To evaluate the alternative theories more systematically, we compare a series of nonnested models. ${ }^{19}$ Let $Y_{i}$ indicate whether the justice voted to concur in a case or not, $x_{i}$ denote the justice's ideal point, $x_{O, i}$ denote the location of the opinion coalition median, and $x_{W, i}$ denote the location of the opinion writer. Further, let $p_{i}$ be a binary indicator of whether the opinion is a plurality opinion or not. The model we estimate to test our main hypothesis is thus:

$$
\begin{aligned}
\operatorname{Pr}\left(Y_{i}=1 \mid \bullet\right)= & \Lambda\left(\gamma_{0}+\gamma_{1}\left[I\left(p_{i}=1\right)\left|x_{i}-x_{W, i}\right|\right.\right. \\
& \left.\left.+I\left(p_{i}=0\right)\left|x_{i}-x_{O, i}\right|\right]\right)
\end{aligned}
$$

$\Lambda$ denotes the cumulative distribution function of the logistic distribution, and $I$ is an indicator function. ${ }^{20} \mathrm{We}$ compare our coalition median model with a model motivated by median justice theory (MJT) and an opinionwriter model, estimated using maximum likelihood. ${ }^{21}$ Estimates for these models with special concurrences and

online Appendix Table 8). Most cases in the database fall out along ideological lines.

${ }^{19}$ The units of analysis are decisions of justices in the majority who are not the opinion writer to file a concurrence. This leaves us with 17,422 justice decisions.

${ }^{20}$ This specification assumes a single parameter characterizes the effects of distance to the opinion writer or distance to the coalition median. In Table 1 of the online appendix, we fit the model separately and show that this assumption is not driving the findings. We stick with a single parameter model because using it biases against finding superiority over the MJT or other models. We also compare our results to a fully saturated model including distance to the median justice, distance to the opinion writer, and distance to the coalition model. Our model outperforms this model (see Table 9, online appendix), which is an extremely strong result.

${ }^{21}$ We report asymptotic standard errors rather than "robust" ones since their use is questionable in all but linear models. The 


\section{TABLE 1 Number of Special Concurrences for Cases with Perfect Spatial Voting for the 1953-2005 Terms. Number of Cases Shows the Total Number of Cases with the Particular Coalition Structure}

\begin{tabular}{|c|c|c|c|c|c|c|c|c|c|}
\hline & 5-4 Right & 6-3 Right & 7-2 Right & 8-1 Right & $\begin{array}{l}\text { Unan- } \\
\text { imous }\end{array}$ & 8-1 Left & 7-2 Left & 6-3 Left & 5-4 Lef \\
\hline Justice 1 & & & & & 171 & 11 & 4 & 1 & 1 \\
\hline Justice 2 & & & & 14 & 142 & 5 & 5 & 3 & 3 \\
\hline Justice 3 & & & 32 & 14 & 114 & 7 & 4 & 5 & 3 \\
\hline Justice 4 & & 21 & 21 & 11 & 118 & 8 & 6 & 2 & 3 \\
\hline Justice 5 & 16 & 8 & 15 & 8 & 75 & 6 & 10 & 14 & 7 \\
\hline Justice 6 & 18 & 7 & 8 & 6 & 86 & 8 & 11 & 12 & \\
\hline Justice 7 & 10 & 5 & 4 & 6 & 75 & 15 & 10 & & \\
\hline Justice 8 & 18 & 14 & 10 & 10 & 147 & 18 & & & \\
\hline Justice 9 & 11 & 6 & 9 & 13 & 158 & & & & \\
\hline Number of Cases & 367 & 253 & 201 & 185 & 1741 & 110 & 110 & 111 & 192 \\
\hline
\end{tabular}

both special and general concurrences are presented in Table $2 .^{22}$ In all models, we find a statistically significant relationship between the distance measures and the propensity to concur, signed in the hypothesized direction. A number of reasons explain why, our arguments about the failings of median justice theory notwithstanding, the relationship between distance to the median justice and propensity to concur is statistically significant. First, the correlation between distance from the coalition median and distance from the Court median is high $(r=0.92)$. Second, while our argument has focused on the boundary case in which justices are unwilling to switch sides, justices may be willing to trade disposition for opinion language in some cases. Finally, given the number of observations, nearly any relationship will be statistically significant. As a result, the critical test of our theory lies in a comparison of models.

Which model is best? One way to compare models is in-sample prediction. However, this is not principled and encourages overfitting. The substantive value

substantive findings do not differ with robust standard errors. To test the robustness of the findings, we refit the models using a random effects logistic regression, clustering by justice and case (online Appendix Table 3). The estimated signs and levels of significance are stable across these specifications. We also reestimated the models excluding unanimous cases, excluding 5-4 cases, excluding both, and including nonperfect spatial voting cases (online Appendix Tables 5-8). The substantive conclusions do not differ.

${ }^{22}$ In a special concurrence, a justice agrees with the disposition but not the rationale given by the Court. In a general concurrence, a justice agrees in part with the rationale. Because general concurrences may reflect minor differences or profound disagreement, they do not "mean the same thing" across cases. As a result, we believe that focusing on special concurrences provides a clearer picture. of our test lies in using statistical models to distinguish between competing explanations. Since the models are not nested, we use the Bayesian Information Criterion (BIC), an approximate Bayes factor, to compare the models (Raftery 1995). The model with the lower BIC is superior. As can be seen in Table 2, our model outperforms both the median justice model and the opinion writer model. ${ }^{23}$

The estimated effects are substantively significant. In Figure 3 we plot the predicted probability of special concurrence (based on the column 1 estimates) for majority opinions. The figure shows that the probability of a special concurrence is $4.7 \%$ when the justice is located at the median of the opinion coalition. The predicted probability increases over fivefold to $25.4 \%$ when the justice is six units away on the Martin-Quinn scale. (The distance between Stevens and Thomas during the 2005 term of the Court is nearly seven points.) These probability differentials are large; when a justice is close to the coalition median, she is predicted to concur only 1 in 20 times, but when she is far, this rises to 1 in 4 times.

In short, the patterns of concurrences on the U.S. Supreme Court are better explained by the distance between a justice and the median member of the signing coalition than by the distance between the justice and

\footnotetext{
${ }^{23}$ One weakness of the BIC is that it is a heuristic and observed differences in BIC do not correspond to probabilities. In online Appendix Table 2 we report the Bayes factors between these four possible models on a base-10 logarithmic scale. The Bayes factor between our model and the others are all large, which suggests that the posterior probability that our model is better than all the others exceeds $99.9 \%$.
} 
TABLE 2 Logistic Regression Estimates for the Alternative, Median Justice Theory (MJT), and Opinion Writer Concurrence Models

\begin{tabular}{|c|c|c|c|c|c|c|}
\hline Covariates & $\begin{array}{l}\text { Coalition } \\
\text { Median } \\
\text { Model }\end{array}$ & $\begin{array}{c}\text { MJT } \\
\text { Model }\end{array}$ & $\begin{array}{c}\text { Opinion } \\
\text { Writer }\end{array}$ & $\begin{array}{c}\text { Coalition } \\
\text { Median } \\
\text { Model } \\
\text { (Including } \\
\text { General) }\end{array}$ & $\begin{array}{c}\text { MJT } \\
\text { Model } \\
\text { (Including } \\
\text { General) }\end{array}$ & $\begin{array}{l}\text { Opinion } \\
\text { Writer } \\
\text { (Including } \\
\text { General) }\end{array}$ \\
\hline Constant & $\begin{array}{c}-3.018 \\
(0.044)\end{array}$ & $\begin{array}{c}-2.701 \\
(0.042)\end{array}$ & $\begin{array}{c}-2.985 \\
(0.050)\end{array}$ & $\begin{array}{c}-2.169 \\
(0.033)\end{array}$ & $\begin{array}{c}-1.994 \\
(0.032)\end{array}$ & $\begin{array}{c}-2.191 \\
(0.038)\end{array}$ \\
\hline $\begin{array}{l}\text { Distance to Coalition } \\
\text { Median (Majority Case) } \\
\text { or Opinion Writer } \\
\text { (Plurality Case) }\end{array}$ & $\begin{array}{c}0.324 \\
(0.017)\end{array}$ & & & $\begin{array}{c}0.229 \\
(0.014)\end{array}$ & & \\
\hline Distance to Court Median & & $\begin{array}{c}0.145 \\
(0.018)\end{array}$ & & & $\begin{array}{c}0.118 \\
(0.015)\end{array}$ & \\
\hline Distance to Opinion Writer & & & $\begin{array}{c}0.200 \\
(0.014)\end{array}$ & & & $\begin{array}{c}0.154 \\
(0.011)\end{array}$ \\
\hline $\mathrm{N}$ & 17422 & 17422 & 17422 & 17422 & 17422 & 17422 \\
\hline Log-Likelihood & -4597.84 & -4733.08 & -4670.80 & -6940.23 & -7031.89 & -6977.29 \\
\hline BIC & 9273.79 & 9544.28 & 9419.73 & 13958.58 & 14141.90 & 14033.29 \\
\hline
\end{tabular}

Note: The second set of models contains both special and general concurrences. The estimates are maximum likelihood, with asymptotic standard errors in parentheses.

the median justice or the opinion writer. Coupled with Clark and Lauderdale's (2010) findings on opinion location, these results provide substantial support for our argument. ${ }^{24}$ The data reflect the model's predictions for opinion location and concurrence behavior.

\section{Conclusion}

Predominant academic and popular views hold that majority opinions of the Supreme Court reflect either the preferences of the Court's median justice or of the opinion's author. The argument we have presented challenges both accounts and highlights the influence of the median member of the signing coalition in shaping opinion content. This result derives from taking account of two facets of judicial decision making that have received little attention in previous models. One is that in crafting legal rules, justices must resolve particular cases, and therefore may have preferences over which party prevails in the dispute before them. The second is the fact that justices who disagree with the rationale offered in an opinion are free

\footnotetext{
${ }^{24}$ In an online appendix, we analyze a saturated model that is identical to Clark and Lauderdale's estimation and find the same results, including a negative sign on distance to the median justice (see online Appendix Table 9). We also perform supplemental analysis that finds support for the influence of the opinion writer in addition to the median of the coalition for majority decisions. These findings are consistent with the findings of the saturated model and suggest support for the agenda-setting opinion writer model in addition to our model.
}

Note: The probabilities are based on model estimates in Table 2, the prediction. 
to write concurrences. Both features imply that justices who agree with the majority on case disposition but are uncomfortable with the rationale offered in the Court's opinion may not want to-and need not— "switch sides" to the minority. This undermines the credibility of a threat to defect and therefore reduces the median justice's bargaining power. Empirical analysis of the ideological position of Supreme Court opinions (Clark and Lauderdale 2010) is consistent with this claim, as is our empirical investigation of concurrence behavior.

The conclusion that the median of the signing coalition is particularly influential in shaping the content of majority opinions has significant implications. For one, it implies that the opinions issued by the Court are less "centrist" (with respect to the Court) than generally believed-opinions will be systematically drawn away from the Court's center to its wings. To illustrate the potential significance of these effects, consider the following illustration. For the data included in our empirical test (the 1953-2005) terms, the median justice in the majority coalition differs from the median justice of the Court in $65.3 \%$ of the cases. The average distance between the median member of the majority coalition and the median justice in these cases is 0.66 on the Martin-Quinn scale. Across terms, this average distance varies from a minimum of .25 to a maximum of 1.13 . To put these numbers into context, the difference in Martin-Quinn scores between justices Kennedy and Rehnquist during the 2003 term was .60, and the difference between Kennedy and Roberts during the 2005 term was .98. In other words, who shapes the content of the opinions is likely to have significant impact on decisions.

This, in turn, implies that there may be less consistency between opinions than we would expect if a single justice is in the proverbial "driver's seat": because the median of the signing coalition can change from decision to decision, we may observe quite different opinions within the same policy area even within the same natural Court. Moreover, the argument has implications for relations within the judicial hierarchy. To the extent that the rules announced by the Court are pulled away from the Court's median justice, lower courts may find themselves in an awkward position: faithful application of the legal rule (which is not located at the position of the median) will result in a disposition that the median justice does not favor-and therefore result in a reversal if the lower court's decision is reviewed. On the other hand, deciding the case at hand in a manner that secures the disposition favored by the median justice of the Supreme Court requires the lower court to announce a legal rule that is inconsistent with the Court's prior decision.
Finally, if correct, our analysis implies that appointments to the Supreme Court, even if they do not change the Court's median, are more significant than is often believed. Consider the reaction to the recent announcement of Justice David Souter's retirement. In its frontpage article on the retirement, the New York Times argued that " $[r]$ eplacing Justice Souter with a liberal would not change the basic makeup of the Court, where he and three other justices hold down the left wing against a conservative caucus of four justices. Justice Anthony Kennedy, a moderate Republican appointee, often provides the swing vote that controls important decisions" (May 2, p. 1). Our argument-and evidence-suggest that the reality of appointments is more complex. To the extent that appointments shift the ideological composition of majority coalitions, and the location of coalition medians, they can have dramatic consequences for the content of opinions.

Naturally, our argument is but a first step in understanding how collegial court bargaining shapes judicial policy. Two issues deserve mention. First, our formal analysis relies on the (strong) assumption that justices care sufficiently about the disposition that they are unwilling to "switch sides." While this is plausible in some cases, in others it may not be so. Importantly, the dynamics we identify are not only relevant to those cases in which the assumption is met. Even if justices are willing to support dispositions with which they disagree, as long as they care independently about the disposition, the bargaining power of the median justice wanes, and the influence of the coalition median increases. This is the case because such preferences introduce an asymmetry into justices' preferences over rules. Although they may be willing to support a disposition with which they disagree, they would prefer to remain on the "right side," even if they must accept a rule that does not reflect their opinions perfectly. This reluctance opens a wedge between the location of majority opinions and the views of the median justice. The more the disposition matters, the more significant this wedge. In other words, our model and median-justice models mark the two end-points of a continuum. Where opinions fall along this continuum depends on the weight placed by justices on the disposition. The fact that our empirical analysis as well as Clark and Lauderdale's (2007) work clearly demonstrate the influence of the coalition median empirically-an influence that is not predicted by existing models of judicial behavior-strongly suggests the relevance of the model for a broad class of Supreme Court decisions.

The second issue is more vexing. Majority opinions are accorded special status in academic analysis and the popular press. They are presumed to create binding precedent. Understanding how bargaining on a collegial 
court affects what goes into such opinions, and which justices are particularly influential, is therefore of interest. At the same time, the content of majority opinions cannot be equated with the "the law" that is created through judicial adjudication. To the extent that "the law" is a function of expectations that lower court judges, policy makers, and potential litigants hold about future decisions, the content of majority opinions is only one ingredient. Concurrences, dissents, judicial appointments, and a host of other factors may shape these expectations as well. While understanding the content of majority opinions is an important step in the challenging endeavor of determining where "the law" rests, it is only a first one.

\section{References}

Bonneau, Chris W., Thomas H. Hammond, Forrest Maltzman, and Paul J. Wahlbeck. 2007. "Agenda Control, the Median Justice, and the Majority Opinion on the U.S. Supreme Court." American Journal of Political Science 51(4): 890-905.

Carrington, Paul D. 1992. "Butterfly Effects: The Possibilities of Law Teaching in a Democracy." Duke Law Journal 41(4): 741-805.

Clark, Tom. 2011. The Limits of Judicial Independence. Cambridge: Cambridge University Press.

Clark, Tom S., and Benjamin Lauderdale. 2010. "Locating Supreme Court Opinions in Doctrine Space." American Journal of Political Science 54(4): 871-90.

Corley, Pamela C. 2010. Concurring Opinion Writing on the U.S. Supreme Court. Albany, NY: SUNY Press.

Epstein, Lee, Daniel E. Hoe, Gary King, and Jeffrey A. Segal. 2005. "The Supreme Court During Crisis: How War Affects Only Non-War Cases.” New York University Law Review 80(1): 1-116.

Epstein, Lee, and Jack Knight. 1998. The Choices Justices Make. Washington, DC: CQ Press.

Ferejohn, John, and Barry Weingast. 1992. "A Positive Theory of Statutory Interpretation." International Review of Law and Economics 12: 263-79.

Hammond, Thomas H., Chris W. Bonneau, and Reginald S. Sheehan. 2005. Strategic Behavior and Policy Choice on the U.S. Supreme Court. Stanford, CA: Stanford University Press.

Haskins, George L., and Herbert A. Johnson. 1981. Foundations of Power: John Marshall, 1801-1815. New York: Macmillan.

Kornhauser, Lewis A. 1992. "Modeling Collegial Courts I: PathDependence." International Review of Law and Economics 12(2): 169-85.

Lax, Jeffrey R. 2007. “Constructing Legal Rules on Appellate Courts.” American Political Science Review 101(3): 591-604.

Lax, Jeffrey R., and Charles M. Cameron. 2007. "Bargaining and Opinion Assignment on the U.S. Supreme Court." Journal of Law, Economics \& Organization 23(2): 276-302.
Maltzman, Forest, James F. Spriggs II, and Paul J. Wahlbeck. 2000. Crafting Law on the Supreme Court. New York: Cambridge University Press.

Martin, Andrew D., and Kevin M. Quinn. 2002. "Dynamic Ideal Point Estimation via MCMC for the U.S. Supreme Court, 1953-1999.” Political Analysis 10(2): 134-53.

Martin, Andrew D., Kevin M. Quinn, and Lee Epstein. 2005. "The Median Justice on the U.S. Supreme Court." North Carolina Law Review 83(5): 1275-1322.

McGuire, Kevin, and Georg Vanberg. 2007. "Mapping the Policies of the US Supreme Court: Data, Opinions, and Constitutional Law." Presented at the 2007 Midwest Political Science Meeting.

Owens, Ryan J. 2010. “The Separation of Powers, Judicial Independence, and Strategic Agenda Setting." American Journal of Political Science 54(2): 412-27.

Raftery, Adrian. 1995. "Bayesian Model Selection in Social Research (with Discussion)." In Sociological Methodology, ed. Peter V. Marsden. Cambridge, MA: Blackwell, 111-96.

Ruckman, P. S. 1993. "The Supreme Court, Critical Nominations, and the Senate Confirmation Process." Journal of Politics 55(3): 793-805.

Segal, Jeffrey. 1997. "Separation of Powers Games in the Positive Theory of Congress and the Courts." American Political Science Review 91(1): 28-44.

Spaeth, Harold J. 2006. "United States Supreme Court Judicial Database, 1953-2005 Terms." [Computer File]. http:// www.as.uky.edu/polisci/ulmerproject/.

Westerland, Chad. 2003. "Who Owns the Majority Opinion? An Examination of Policy Making on the U.S. Supreme Court." Presented at the annual meeting of the American Political Science Association, Philadelphia.

\section{Supporting Information}

Additional Supporting Information may be found in the online version of this article:

Figure A1: Illustration of major result, showing concurrence rates using binned ranges (removed from manuscript due to space concerns).

Table A1: Logistic regression estimates for the alternative models, separate analyses for plurality and majority cases. Models 1 and 2 are for special concurrences only; Models 3 and 4 for special and general concurrences.

Table A2: Bayes factors (logarithm base-10) for the four theoretically supported models.

Table A3: Random effects logistic regression estimates for the alternative models. Models 1 and 2 are for special concurrences only; Models 3 and 4 for special and general concurrences. Models 1 and 3 include a random effect for each case; Models 2 and 4 contain a random effect for each justice.

Table A4: Logistic regression estimates for the alternative models, separate analyses for plurality and majority cases. 
Models 1 and 2 are for special concurrences only; Models 3 and 4 for special and general concurrences.

Table A5: Logistic regression estimates for the alternative and MJT models, excluding unanimous cases.

Table A6: Logistic regression estimates for the alternative and MJT models, excluding 5-4 cases.

Table A7: Logistic regression estimates for the alternative and MJT models, excluding unanimous and $5-4$ cases.

Table A8: Logistic regression estimates for the alternative and MJT models, including cases with nonperfect spatial voting.
Table A9: Logistic regression estimates from a fully saturated model including all covariates, for special and all concurrences.

Table A10: Logistic regression estimates for the same models as reported in Table 2 in the text with the docket, rather than the citation, as the unit of analysis.

Please note: Wiley-Blackwell is not responsible for the content or functionality of any supporting materials supplied by the authors. Any queries (other than missing material) should be directed to the corresponding author for the article. 